\title{
Analisis Kebutuhan Pengembangan Buku Saku Matematika Berbasis Mind Map
}

\author{
Nanang Abdul Salam ${ }^{1 *}$, Yayan Diansyah ${ }^{2}$, Wahyu Hidayat ${ }^{3}$ \\ 1,2,3 IKIP Siliwangi \\ *nanangabdulsalam302@gmail.com
}

\begin{tabular}{|l|l|l|l|}
\hline Received : 17-06-2020 & Revised: 26-08-2020 & Accepted: $19-09-2020$ & Published: 05-12-2020 \\
\hline
\end{tabular}

\begin{abstract}
ABSTRAK
Penelitian ini bertujuan untuk mengeksplorasi potensi pengembangan buku saku berbasis Mind Map. Buku saku berbasis Mind Map merupakan buku pendukung berukuran lebih kecil dari buku standar, secara sistematis sesuai dengan prinsip kerja otak. Penelitian ini dilatar belakangi siswa memerlukan bahan ajar yang praktis ketika belajar. Penelitian ini merupakan penelitian kualitatif deskriptif dengan metode survey. Subjek penelitian ini adalah siswa di salah satu SMP Negeri di Kabupaten Cianjur. Data dikumpulkan menggunakan instrumen yang divalidasi oleh ahli dan diuji pada 64 siswa tahun pelajaran 2019/2020. Hasil penelitian ini menunjukkan bahwa 82,8\% responden menjawab matematika sulit dipelajari. Materi yang sulit $61,3 \%$ responden menjawab materi Teorema Pythagoras. Kesulitan belajar matematika disebabkan adanya rumus yang harus dihafalkan pada materi tersebut berdasarkan $70,3 \%$ responden. Guru berpendapat bahwa sumber belajar tambahan diharapkan dapat merangsang siswa untuk meningkatkan hasil belajar. Adanya sumber belajar diharapkan dapat menjadi solusi terhadap kesulitan belajar yang dialami siswa. Berdasarkan data ini, dapat disimpulkan bahwa siswa membutuhkan sumber belajar yang inovatif dan menarik
\end{abstract}

Kata Kunci: Buku saku, Mind Map, Bahan Ajar

\begin{abstract}
This study aims to explore the potential for developing a Mind Map based pocket book. Mind Map based books are supporting books smaller than standard books, systematically in accordance with the working principles of the brain. This research is motivated by students need practical teaching materials when learning. This research is a descriptive qualitative research with survey method. The subjects of this study were students in one of the State Junior High Schools in Cianjur. Data were collected using an instrument validated by experts and tested on 64 students in the 2019/2020 school academic. The results of this study indicate that $82.8 \%$ of respondents answered mathematics question is difficult to learn. Difficult material 61.3\% of respondents answered the Pythagorean Theorem material. The difficulty of learning mathematics is due to the formula that must be memorized on the material based on $70.3 \%$ of respondents. The teacher believes that additional learning resources are expected to stimulate students to improve learning outcomes. The existence of learning resources is expected to be a solution of the learning difficulties experienced by students. Based on this data, it can be concluded that students need innovative and interesting learning resources.
\end{abstract}

Keywords: Pocket book, Mind Map, Teaching Materials

\section{PENDAHULUAN}

Belajar merupakan suatu proses perubahan tingkah laku sebagai hasil dari interaksi dengan lingkungannya dalam memenuhi kebutuhan hidupnya (Daryanto, 2010; Maskur et 
al., 2020; Septian, Darhim, \& Prabawanto, 2020). Pembelajaran merupakan aktivitas dan proses yang sistematis dan sistemik yang terdiri dari beberapa komponen yaitu: guru, kurikulum, anak didik, fasilitas dan administrasi. Masing-masing komponen tidak bersifat parsial (terpisah) atau berjalan sendiri-sendiri, tetapi harus berjalan secara teratur, saling bergantung, komplementer dan berkesinambungan (Suryanda et al, 2020). Pembelajaran melibatkan berbagai unsur: metode, penggunaan media (cetak, visual/gambar, audio dan multimedia) (Hendriawan \& Septian, 2019; Jusniani, 2018; Rahmawati, 2018; Suparman, 2014). Untuk itu diperlukan rancangan dan pengelolaan belajar serta penggunaan sumber belajar yang dikembangkan dalam rangka mencapai tujuan pembelajaran.

Sumber belajar utama bagi siswa adalah buku paket atau buku teks siswa yang telah ditetapkan pemerintah (Fajriana et al, 2017). Penggunaan buku paket akan lebih mempercepat pencapaian tujuan pembelajaran apabila siswa melengkapinya dengan sumber belajar lain yang sesuai dengan materi pelajaran tersebut. Hal tersebut dikuatkan melalui Peraturan Menteri Pendidikan Nasional RI, Nomor 2 tahun 2008 bab V pasal 6 ayat (2) tentang penggunaan buku di satuan pendidikan yang intinya menyatakan "selain buku teks, pendidik dapat menggunakan buku panduan pendidik, buku pengayaan, dan buku referensi dalam proses pembelajaran”. Fungsi buku dijelaskan pada ayat (3) yaitu "untuk menambah pengetahuan dan wawasan peserta didik". Berdasarkan penjelasan tersebut maka guru dan siswa dapat menggunakan buku teks lain sebagai buku teks penunjang/pelengkap. Pada saat ini persaingan yang semakin kompetitif, siswa perlu memiliki kemampuan memperoleh, memilih dan mengolah informasi untuk bertahan pada keadaan yang selalu berubah, tidak pasti dan kompetitif. Kemampuan ini membutuhkan kemampuan berpikir kritis, sistematis, logis, kreatif dan kemampuan bekerjasama yang efektif. Cara berpikir seperti ini dapat dikembangkan melalui belajar matematika, karena matematika memiliki struktur dan keterkaitan yang kuat dan jelas antar konsepnya sehingga memungkinkan siswa terampil berpikir rasional. Dengan demikian untuk merancang pembelajaran matematika diperlukan bahan dan alat dukung seperti: penggunaan media pembelajaran, sarana laboratorium, laboratoium virtual, dll) yang tepat. Karakteristik materi matematika memerlukan kemampuan berpikir tingkat tinggi seperti pemikiran secara kritis, logis, analitis, dan bahkan kadang-kadang memerlukan pemikiran kombinatorial.

Bahan ajar merupakan segala bentuk bahan yang digunakan untuk membantu guru/instruktur dalam melaksanakan kegiatan belajar mengajar di kelas (Fatwa, Septian, \& Inayah, 2019). Bahan yang dimaksud bisa berupa tertulis maupun bahan tidak tertulis. Masih menurut (Amri \& Ahmadi, 2010) jenis-jenis bahan ajar yaitu: a) bahan ajar pandang (visual) 
terdiri dari bahan cetak (printed) seperti hand out, buku, modul, lembar kerja siswa, brosur, leaflet, wallchart, foto/gambar, dan non cetak (non printed), seperti model/maket. b) bahan ajar dengar (audio) seperti kaset, radio, piringan hitam, dan compact disk audio. c) bahan ajar pandang dengar (audio visual) seperti compact disk, film. d) bahan ajar multimedia interaktif (interaktive teaching maaterial) seperti CAI (Computer Assisted Instruction), compact disk (CD) multimedia pembelajaran interaktif, dan bahan ajar berbasis web (web based learning materials).

Berdasarkan paparan di atas, maka materi matematika akan sulit dipahami jika tidak didukung dengan data visual yang akan merangsang otak manusia untuk mengingat dan memahami maksud dari konsep yang dipaparkan (Budiman \& Esvigi, 2017; Djasmita, 2017). Dengan kata lain untuk memaksimalkan usaha agar materi matematika yang dianggap masih sulit dipahami oleh Sebagian siswa diperlukan bahan ajar yang dapat membantu guru melaksanakan kegiatan belajar di kelas.

Berdasarkan hasil observasi pada bulan Januari 2020 di perpustakaan sekolah dan beberapa toko buku online dan non-online, ketersediaan buku dengan karakteristik demikian sangatlah langka dijumpai. Apabila dijumpai, maka buku yang ada relatif besar sekitar 25 $\mathrm{cm}$ x $17 \mathrm{~cm}$ dan tebal. Selain itu, tampilan yang monoton dalam hal tulisan dan tata letak, serta gambar tanpa warna, atau berwarna namun rendah resolusinya.

Peserta didik membutuhkan bahan ajar agar materi tersebut lebih efisien, menarik dan mudah dibawah kemana saja untuk belajar. Salah satu alternatifnya adalah dengan mengembangkan buku saku. Buku saku yang dimaksud adalah buku yang menyerupai modul, dengan ukuran yang kecil, dapat disimpan dalam saku, mudah dibawa kemana-mana dan dapat dipelajari setiap saat (Cahyono et al, 2018). Buku saku ini diharapkan mampu menjadi salah satu sumber belajar untuk menarik perhatian dan minat peserta didik dalam pembelajaran matematika pada khususnya. Sehingga prestasi belajar peserta didik diharapkan dapat meningkat.

Keberadaan buku paket dan buku saku matematika juga belum sepenuhnya dimanfaatkan siswa sebagai sumber belajar, hal ini karena buku paket (buku siswa) yang disediakan pemerintah dan buku saku yang ada hanya menampilkan contoh-contoh soal dengan tampilan data linear yang kurang merangsang siswa untuk berpikir lebih dinamis, bahkan ada kalanya mereka dihadapkan pada kondisi sekolah dan kondisi ekonomi yang kurang menguntungkan sehingga mereka tidak mendapatkan sumber belajar sama sekali. Berdasarkan hal tersebut, maka kebutuhan buku saku yang dibuat menarik dengan beragam data visual yang mengacu tampilan yang dinamis dengan konsep mengikuti kerja otak 
berupa Mind Map menjadi sesuatu yang dibutuhkan.

Berdasarkan paparan di atas, sesuai dengan tujuan penelitan yaitu untuk mengeksplorasi potensi pengembangan buku saku berbasis Mind Map maka perlu dilakukannya penelusuran lebih untuk melihat apakah pengembangan buku saku berbasis Mind Map merupakan suatu kebutuhan. Penelitian ini merupakan penelitian pendahuluan dari penelitian pengembangan media belajar mandiri bagi siswa yang mudah dibawa dan mengikuti cara kerja otak manusia. Penelitian ini ingin menggali kebutuhan akan sumber belajar mandiri matematika yang berbasis Mind Map.

\section{METODE PENELITIAN}

Penelitian ini menggunakan metode deskriptif dengan teknik survei. Metode penelitian deskriptif sebagai penelitian yang dikakukan untuk mengetahui nilai variabel mandiri baik satu variabel atau lebih (independent) tanpa membuat perbandingan, atau menghubungkan dengan variabel yang lain (Sugiyono, 2018). Adapun metode survey yaitu metode yang digunakan untuk mendapatkan data dari tempat tertentu yang alamiah (bukan buatan), tetapi peneliti melakukan perlakuan dalam pengumpulan data, misalnya dengan menyebarkan kuesioner, tes, wawancara terstuktur, dan sebagainya (Sugiyono, 2018). Sampel penelitian sebanyak 64 orang siswa dari salah satu SMP Negeri di Cianjur kelas VIII tahun pelajaran 2019/2020 dan dua orang guru matematika di salah satu SMP Negeri dan SMP Swasta di Cianjur. Dengan menggunakan instrumen penilaian kebutuhan data diambil melalui teknik paper and pencil test. Hasil data yang telah terkumpul kemudian diolah menggunakan teknik analisis persentase, dan pengolahan data akan dilakukan dengan menggunakan alat bantu aplikasi Microsoft Office Excel.

\section{HASIL DAN PEMBAHASAN}

Berdasarkan hasil observasi dan penelusuran buku paket dan buku saku pada perpustakaan di sekolah dan toko online ataupun non-online, keberadaan buku paket ataupun buku penunjang yang lainnya yang digunakan sebagai bahan pendamping pada kegiatan pemebelajaran didapati bahwa buku saku matematika tersebut merupakan buku ringkasan materi untuk persiapan ujian nasional, dan materi latihan soal serta sangat minim ilustrasi dan warna, sehingga membuat jenuh pembaca. Beberapa buku tersebut dapat dilihat pada Tabel 1. 
Tabel 1. Buku yang Digunakan dan Beredar di Pasaran

\begin{tabular}{clllll}
\hline No & Judul & Pengarang & Tahun & Penerbit & Cover \\
\hline 1 & Buku Siswa & Abdur Rahman & 2017 & Kementerian & \\
& Matematika & As'ari, Mohammad & & Pendidikan & \\
& Untuk Kelas VIII & Tohir, Erik Valentino, & dan & \\
& SMP/MTs & Zainul Imron, Ibnu & Kebudayaan & \\
& & Taufiq, Nuniek & & \\
& Slamet Hariarti, dan & & & \\
& Dana Arief Lukmana. & & \\
& & & &
\end{tabular}

\begin{tabular}{lll|l}
\hline Hafal Mahir Teori & Uly Amalia \\
dan Rumus & Gatematika SMP \\
kelas 7-8-9 & & \\
TEORI DAH RUMUS \\
MATEMATIKA
\end{tabular}

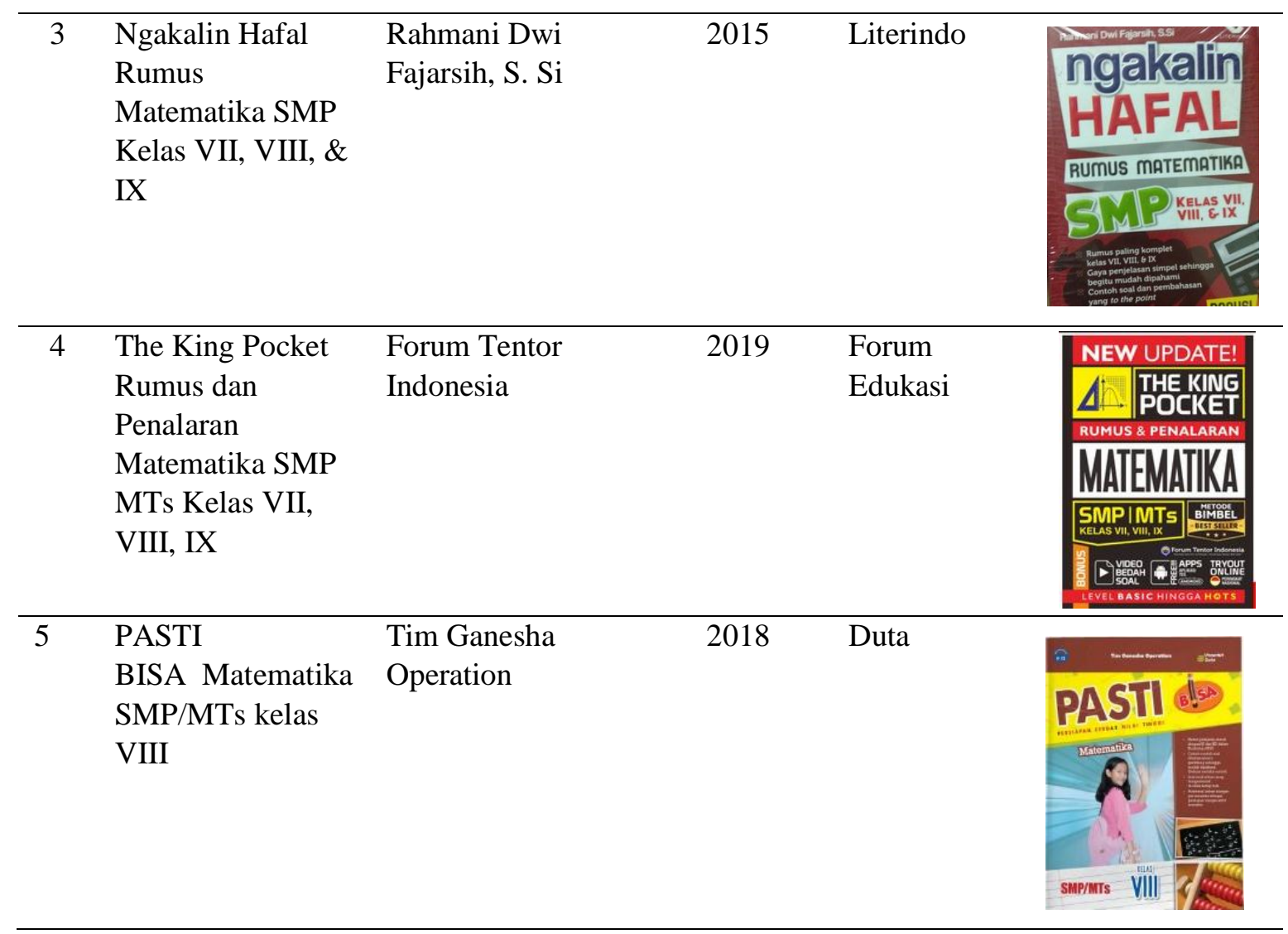

Hasil penelitian berdasarkan penggalian informasi terhadap siswa (responden 64 siswa) mengenai kebutuhan akan adanya buku saku matematika berbasis Mind Map dapat dilihat pada Tabel 2 . 
Tabel 2. Rekapitulasi Hasil Analisis Kebutuhan

\begin{tabular}{|c|c|c|}
\hline No & Pernyataan & Hasil Temuan \\
\hline 1 & $\begin{array}{l}\text { Matematika termasuk mata } \\
\text { pelajaran yang sulit } \\
\text { Ket: responden } 64 \text { orang }\end{array}$ & $\begin{array}{l}82,8 \% \text { menyatakan ya } \\
17,2 \% \text { menyatakan tidak }\end{array}$ \\
\hline 2 & $\begin{array}{l}\text { Alasan materi Teorema Pythagoras } \\
\text { sulit dipahami } \\
\text { (jawaban boleh lebih dari 1) } \\
\text { Ket: responden } 64 \text { orang }\end{array}$ & $\begin{array}{l}70,3 \% \text { terlalu banyak hafalan rumus } \\
39,1 \% \text { penyajian guru kurang variatif } \\
73,4 \% \text { belum digunakan sumber belajar } \\
\text { yang menarik } \\
53,1 \% \text { materi matematika terlalu abstrak } \\
26,6 \% \text { jam pelajaran yang kurang sesuai } \\
\text { dengan banyaknya materi }\end{array}$ \\
\hline 3 & $\begin{array}{l}\text { Jenis sumber belajar yang sering } \\
\text { digunakan pada pembelajaran } \\
\text { matematika } \\
\text { (jawaban boleh lebih dari 1) } \\
\text { Ket: responden } 64 \text { orang }\end{array}$ & $\begin{array}{l}89,1 \% \text { menggunakan buku paket } \\
54,7 \% \text { materi yang disampaikan guru } \\
14,1 \% \text { internet sebagai sumber informasi } \\
10,9 \% \text { menggunakan lingkungan } \\
0,0 \% \text { menggunakan modul } \\
0,0 \% \text { menggunakan LKS } \\
1,6 \% \text { menggunakan sumber belajar lain }\end{array}$ \\
\hline 4 & $\begin{array}{l}\text { Peranan Mind Map bagi siswa } \\
\text { dalam memahami pelajaran } \\
\text { Ket: responden } 64 \text { orang }\end{array}$ & $\begin{array}{l}76,6 \% \text { menatakan Mind Map sangat } \\
\text { membantu memahami pelajaran } \\
23,4 \% \text { menyatakan tidak membantu } \\
\text { memahami pelajaran (kurang paham } \\
\text { dengan penggunaan Mind Map) }\end{array}$ \\
\hline 5 & $\begin{array}{l}\text { Materi matematika lebih mudah } \\
\text { dipahami dengan bantuan Mind } \\
\text { Map } \\
\text { Ket: responden } 64 \text { orang }\end{array}$ & $\begin{array}{l}87,5 \% \text { menyatakan ya } \\
12,5 \% \text { menyatakan tidak }\end{array}$ \\
\hline 6 & $\begin{array}{l}\text { Materi yang cocok diterapkan pada } \\
\text { buku saku matematika berbasis } \\
\text { Mind Map } \\
\text { (jawaban boleh lebih dari 1) } \\
\text { Ket: responden } 64 \text { orang }\end{array}$ & $\begin{array}{l}81,3 \% \text { menyatakan cocok untuk semua } \\
\text { materi } \\
76,6 \% \text { menyatakan cocok pada materi } \\
\text { Teorema Pythagoras } \\
70,3 \% \text { menyatakan cocok pada materi } \\
\text { segiempat dan segitiga } \\
73,4 \text { menyatakan cocok pada materi } \\
\text { aritmetika sosial } \\
71,9 \% \text { menyatakan cocok pada materi } \\
\text { Statistika }\end{array}$ \\
\hline 7 & $\begin{array}{l}\text { Saran dari siswa untuk } \\
\text { pengembangan buku saku } \\
\text { Matematika berbasis Mind Map } \\
\text { Ket: responden } 64 \text { orang }\end{array}$ & $\begin{array}{l}\text { Lebih banyak gambar, Mind Map } \\
\text { berwarna, bahasa komunikatif dan tidak } \\
\text { Panjang, tulisan berwarna, sertakan blok } \\
\text { warna agar mudah diingat, beri tips cara } \\
\text { mudah untuk menghapal materi } \\
\text { matematika, sertakan tutorial cara } \\
\text { membaca dan memahami Mind Map-nya, } \\
\text { sertakan informasi aplikatif yang dekat } \\
\text { dengan kehidupan sehari-hari. }\end{array}$ \\
\hline
\end{tabular}

Pada Tabel 2, memperlihatkan bahwa sebanyak 53 responden (82,8\%) menyatakan materi matematika termasuk sulit untuk dipelajari, Kesulitan belajar siswa didominasi oleh adanya rumus yang yang harus dihafalkan pada materi tersebut yang diungkapkan oleh 
sebanyak 45 responden (70,3\%). Namun demikian sebanyak 25 responden $(39,1 \%)$ menyatakan bahwa sulitnya materi matematika karena cara penyajian guru yang kurang variatif, dan belum digunakannya sumber belajar yang menarik ( 47 responden $=73,4 \%$ ). Hal ini menjelaskan bahwa, apabila sumber belajar menarik responden untuk membaca dan disampaikan dengan sangat menarik dan banyak variasi, maka membuat responden lebih tertarik dan termotivasi serta akan mengembangkan kreativitasnya dan hal ini memberi peluang bagi responden untuk memahami materi biologi lebih baik. Hal ini sejalan dengan hasil penelitian (Djasmita, 2017).

Data juga menunjukkan bahwa sebesar $89,1 \%$ dari 64 responden yang disurvei memilih menggunakan buku paket saat belajar. Hal ini merupakan suatu potensi atau peluang guru untuk meningkatkan prestasi siswa dengan menggunakan buku teks baik buku teks utama maupun buku teks penunjang (Su'udiah et al, 2016), terlebih apabila siswa didorong untuk mengajukan pertanyaan saat mereka membaca, mencari jawaban dalam teks dan mengidentifikasi sumber-sumber lain untuk mengeksplorasi ide-ide dari informasi yang mereka temui, mereka akan menjadi pembaca aktif dan mendapatkan manfaat maksimal dari buku yang mereka baca, sehingga buku penunjang dengan banyak gambar/ilustrasi, bahasa komunikatif, variasi warna dalam hal tulisan, dan informasi aplikatif yang dekat dengan kehidupan sehari-hari serta diringkas dengan bentuk Mind Map yang berwarna, menjadi suatu kebutuhan menurut responden. Hal ini sejalan dengan penelitian (Elita, 2018).

Setelah melakukan pengambilan informasi kebutuhan siswa, wawancara dengan 2 orang guru matematika kelas VIII dari dua sekolah berbeda yang dilakukan pada bulan Februari 2020. Wawancara dilakukan dengan pertanyaan seputar pembelajaran di kelas. Pertanyaan wawancara diantaranya adalah "Apakah kesulitan-kesulitan yang Bapak/lbu hadapi ketika menyampaikan materi?" untuk pertanyaan ini, responden guru memberi tanggapan berupa kesulitan dalam mencari contoh untuk tiap materi yang dekat dengan kehidupan siswa.

Terkait dengan pertanyaan sumber belajar yang disarankan oleh guru untuk dipelajari siswa, responden guru menjawab lebih sering menyarankan membaca buku paket pelajaran. Dengan alasan buku tersebut sudah dimiliki oleh siswa melalui buku yang dipinjamkan ke siswa yang di danai dari dana Bantuan Operasional Sekolah (BOS). Namun disisi lain menurut mereka ketersediaan buku paket di sekolah pun terkadang terbatas, yang seharusnya satu siswa satu buku adakalanya mereka satu buku untuk dua siswa.

Berdasarkan hasil wawancara, didapatkan pula pernyataan responden terkait penggunaan Mind Map dalam pembelajaran Matematika. Responden mengungkapkan 
bahwa Mind Map diperlukan dalam pembelajaran matematika, khusus pada kelas VIII terutama pada materi Teorema Pythagoras, kalaupun ada pada buku siswa, Mind Map nya pun kurang mengikuti apa yang dianjurkan oleh Tony Buzan tentang cara pembuatannya.

Adapun pertanyaan terkait dengan buku saku sebagai buku penunjang, jawaban guru berkisar pada kemungkinan dapat membantu siswa dalam mempelajari, karena kepraktisan untuk dibawa. Namun, setelah diberikan contoh sedikit ilustrasi perencanaan buku saku matematika berbasis Mind Map yang akan dikembangkan, maka responden guru memberikan tanggapan positif. Tanggapan positif ini mungkin dikarenakan, buku saku matematika berbasis Mind Map yang direncanakan ini sangat menarik, penuh warna dan variasi tampilan dan desain serta dari segi konten tidak keluar dari konsep dan tuntutan kurikulum. Hal ini sesuai dengan pendapat (Monariska, 2017; Wibowo \& Suryani, 2013) media cetak sebagai media intervensi yang digunakan diantaranya harus menimbulkan minat pada kelompok sasaran untuk membaca pesan yang terdapat didalamnya.

Memahami pentingnya penggunaan sumber belajar matematika tersebut, maka diperlukan data awal untuk menguatkan urgensi dari pengembangan sumber belajar yang dimaksud. Hasil temuan ini selanjutnya akan diteruskan pada sebuah penelitian Research and Development $(R \& D)$ dengan model pengembangan versi ADDIE. Model ADDIE adalah salah satu model yang umum digunakan di bidang desain instruksional dan panduan untuk memproduksi sebuah desain yang efektif (Dijkstra K, Kipping J, 2015; Widyastuti \& Susiana, 2019). Desain instruksional dikenal dengan teknologi pembelajaran. Ini berarti proses sistematis yang membantu dalam menciptakan dan mengembangkan bahan ajar yang efektif, menarik, dan efisien dalam lingkungan yang mendukung dengan menggunakan seni, Ilmu pengetahuan, pembelajaran, dan teori instruksional (Aldoobie, 2015 dalam Cahyono et al., 2018) untuk dikembangkan menjadi buku saku matematika berbasis Mind Map dan kemudian dilakukan validasi, baik validasi terhadap materi, validasi terhadap bahasa yang digunakan serta validasi terhadap media (Ainurrizqiyah, Mulyono, \& Sutarto, 2015; Hendriawan \& Septian, 2019).

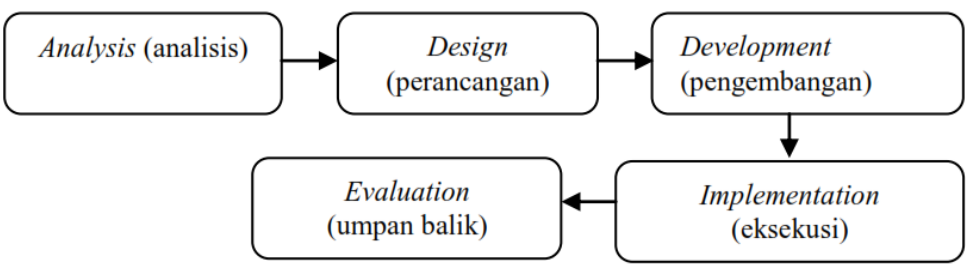

Gambar 1. Tahap Pengembangan Model ADDIE 


\section{KESIMPULAN}

Penelitian ini menyimpulkan, bahwa pengembangan media pembelajaran mandiri berupa buku saku berbasis Mind Map sangat dibutuhkan siswa. Perencanaan pengembangannya yang mengikuti sistem kerja otak, bersifat dinamis dengan beragam data visual, variasi tampilan, dan pewarnaan (color full) menjadikan pengembangannya sangat diharapkan. Keberhasilan dari pengembangan buku saku berbasis Mind Map ini sebagai kelanjutan penelitian adalah perancangan desain buku saku, sehingga dibutuhkan kerjasama/kolaborasi riset dengan berbagai yang menguasai desain grafis.

\section{REFERENSI}

Ainurrizqiyah, Z., Mulyono, \& Sutarto, H. (2015). Keefektifan Model PjBL dengan Tugas Creative Mind-Map untuk Meningkatkan Koneksi Matematik Siswa. Unnes Journal of Mathematics Education., 4(2), 172-179. https://doi.org/10.15294/ujme.v4i2.7600

Amri, S., \& Ahmadi, I. K. (2010). Konstruksi Pengembangan Pembelajaran. Jakarta: Prestasi Pustaka.

Budiman, H., \& Esvigi, I. (2017). Implementasi Strategi Mathematical Habits of Mind (MHM) Berbantuan Multimedia untuk Meningkatkan Kemampuan Berpikir Kritis Siswa. PRISMA, 6(1). https://doi.org/10.35194/jp.v6i1.26

Cahyono, B., Tsani, D. F., \& Rahma, A. (2018). Pengembangan Buku Saku Matematika Berbasis Karakter pada Materi Trigonometri. Jurnal Phenomenon, 8(2), 185-199.

Daryanto, D. (2010). Belajar dan Mengajar. Bandung: CV. Yrama Widya.

Dijkstra K, Kipping J, M. N. (2015). The ADDIE Model: Instructional Design. Educational Technology, 44(4), 447-678. https://doi.org/10.1017/CBO9781107415324.004

Djasmita, N. K. (2017). Pengaruh Metode Pembelajaran Peta Konsep Berbasis Media Visual Terhadap Kemampuan Berpikir Kreatif dan Motivasi Belajar Peserta Didik Kelas $X$. UIN Raden Intan Lampung.

Elita, U. (2018). Peningkatan Hasil Belajar Menggunakan Metode Pembelajaran Mind Mapping. BIOEDUSAINS: Jurnal Pendidikan Biologi Dan Sains, 1(2), 177-182.

Fajriana, N., Abdullah, A., \& Safrida, S. (2017). Analisis Miskonsepsi Buku Teks Pelajaran Biologi Kelas XI Semester 1 SMAN di Kota Banda Aceh. BIOTIK: Jurnal Ilmiah Biologi Teknologi Dan Kependidikan, 4(1), 60-65.

Fatwa, V. C., Septian, A., \& Inayah, S. (2019). Kemampuan Literasi Matematis Siswa melalui Model Pembelajaran Problem Based Instruction. Mosharafa: Jurnal Pendidikan Matematika, 8(3), 389-398.

Hendriawan, M. A., \& Septian, A. (2019). Pengembangan JiMath Sebagai Multimedia Pembelajaran Matematika Berbasis Android Untuk Siswa Sekolah Menengah Atas. IndoMath: Indonesia Mathematics 45. https://doi.org/10.30738/indomath.v2i1.2785

Jusniani, N. (2018). Analisis Kesalahan Jawaban Siswa pada Kemampuan Pemahaman Matematis melalui Pembelajaran Kontekstual. PRISMA, $\quad 7(1), \quad 82$. https://doi.org/10.35194/jp.v7i1.361

Maskur, R., Sumarno, Rahmawati, Y., Pradana, K., Syazali, M., Septian, A., \& Palupi, E. K. (2020). The effectiveness of problem based learning and aptitude treatment interaction in improving mathematical creative thinking skills on curriculum 2013. European Journal of Educational Research, 9(1), 375-383. https://doi.org/10.12973/eu- 
jer.9.1.375

Monariska, E. (2017). Penerapan Metode Mind Mapping untuk Meningkatkan Kemampuan Pemahaman Konsep Matematis Mahasiswa pada Mata Kuliah Kalkulus I. PRISMA, 6(1), 17-31. https://doi.org/10.35194/jp.v6i1.25

Rahmawati, N. I. (2018). Pemanfaatan ICT dalam Meningkatkan Kemampuan Literasi Matematika. PRISMA, 1, 381-387.

Septian, A., Darhim, \& Prabawanto, S. (2020). Geogebra in integral areas to improve mathematical representation ability. Journal of Physics: Conference Series, 1613(1), 12035. https://doi.org/10.1088/1742-6596/1613/1/012035

Su'udiah, F., Degeng, I. N. S., \& Kuswandi, D. (2016). Pengembangan Buku Teks Tematik Berbasis Kontekstual. Jurnal Pendidikan: Teori, Penelitian, Dan Pengembangan, 1(9), 1744-1748.

Sugiyono. (2018). Metode Penelitian Kuantitatif, Kualitatif, dan $R \&$ D. Bandung: Alfabeta.

Suparman, M. A. (2014). Desain Instruksional Modern (Edisi Keempat). Jakarta: Airlangga. Suryanda, A., Azrai, E. P., \& Julita, A. (n.d.). Analisi Kebutuhan Pengembangan Buku Saku Biologi Berbasis Mind Map (BIOMAP). Jurnal Pendidikan Matematika Dan IPA, 11(1), 86-98.

Wibowo, S., \& Suryani, D. (2013). Pengaruh Promosi Kesehatan Metode Audio Visual Dan Metode Buku Saku Terhadap Peningkatan Pengetahuan Penggunaan Monosodium Glutamat (Msg) Pada Ibu Rumah Tangga. Jurnal Kesehatan Masyarakat (Journal of Public Health), 7(2).

Widyastuti, E., \& Susiana. (2019). Using the ADDIE model to develop learning material for actuarial mathematics. Journal of Physics: Conference Series, 1188(1). https://doi.org/10.1088/1742-6596/1188/1/012052 